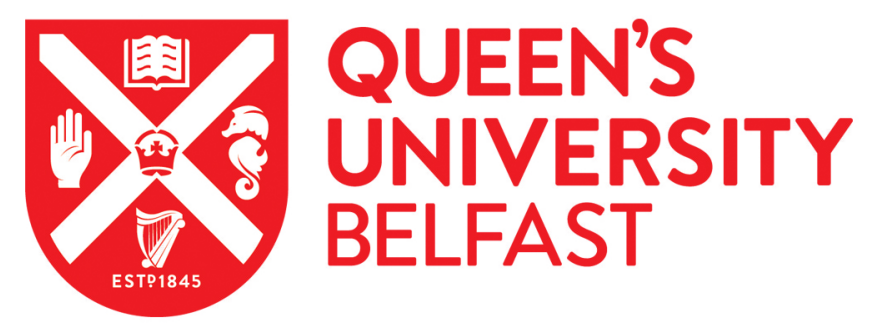

\title{
The Mediating Role of Distress Tolerance in the Relationship Between Childhood Maltreatment and Mental Health Outcomes Among University Students
}

Robinson, M., Ross, J., Fletcher, S., Burns, C. R., Lagdon, S., \& Armour, C. (2021). The Mediating Role of Distress Tolerance in the Relationship Between Childhood Maltreatment and Mental Health Outcomes Among University Students. Journal of Interpersonal Violence, 36(15), 7249-7273.

https://doi.org/10.1177/0886260519835002

\section{Published in:}

Journal of Interpersonal Violence

\section{Document Version:}

Peer reviewed version

Queen's University Belfast - Research Portal:

Link to publication record in Queen's University Belfast Research Portal

\section{Publisher rights}

Copyright 2019 SAGE. This work is made available online in accordance with the publisher's policies. Please refer to any applicable terms of use of the publisher.

\section{General rights}

Copyright for the publications made accessible via the Queen's University Belfast Research Portal is retained by the author(s) and / or other copyright owners and it is a condition of accessing these publications that users recognise and abide by the legal requirements associated with these rights.

Take down policy

The Research Portal is Queen's institutional repository that provides access to Queen's research output. Every effort has been made to ensure that content in the Research Portal does not infringe any person's rights, or applicable UK laws. If you discover content in the Research Portal that you believe breaches copyright or violates any law, please contact openaccess@qub.ac.uk. 


\section{The Mediating Role of Distress Tolerance in the Relationship between Childhood Maltreatment and}

\section{Mental Health Outcomes Among University Students}

Martin Robinson ${ }^{1}$, Jana Ross ${ }^{1}$, Shelley Fletcher ${ }^{1}$, Carol Rhonda Burns ${ }^{1}$, Susan Lagdon ${ }^{2}, \&$ Cherie $\operatorname{Armour}^{1 *}$

Author Affiliations:

${ }^{1}$ Psychology Research Institute, Ulster University, Coleraine, Northern Ireland, UK

${ }^{2}$ School of Nursing and Midwifery, Queens University, Belfast, Northern Ireland, UK

Emails: MR= martinfrobinson@gmail.com, JR=j.ross@ulster.ac.uk, SF = fletcher-

s4@email.ulster.ac.uk, CRB = burns-cr@email.ulster.ac.uk, SL= lagdon-

$\underline{\text { s@email.ulster.ac.uk, }}$ CA = $\underline{\text { armour.cherie@gmail.com }}$

*Address correspondence to:

Cherie Armour, Psychology Research Institute, Ulster University, Coleraine, Northern Ireland, UK, BT52 1SA. Email: armour.cherie@gmail.com; Phone: (0044) 02870123374.

The authors have no funding sources or additional acknowledgements or credits to declare. 


\begin{abstract}
A wealth of empirical literature has documented that the experience of childhood maltreatment is related to an increased risk for the development of psychopathologies in adulthood. Empirical studies examining the factors that could possibly explain this relationship, however, remain sparse. The emerging literature on Distress Tolerance suggests that it could possibly act as an explanatory or mediating factor within this relationship. The current study therefore examined the mediating role of Distress Tolerance in the relationship between childhood maltreatment and psychopathology (PTSD, depression, anxiety and alcohol use $)$ in adulthood in a university student population sample $(N=642)$. Results showed that childhood maltreatment was positively associated with caseness for all mental health outcomes under investigation. It was also found that individuals with higher levels of Distress Tolerance were less likely to experience adverse mental health outcomes. The results of the mediation analysis indicated that the exposure to childhood maltreatment remained associated with elevated risk for being in the symptomatic group across mental health outcomes and that Distress Tolerance significantly mediated this relationship. These results provide insight into the relationship between childhood maltreatment and mental ill-health later in life, highlighting the importance of considering Distress Tolerance as a potential risk and resilience factor in this relationship.
\end{abstract}


Mediating role of distress tolerance

\section{Introduction}

Despite widespread acknowledgement of the impact of childhood maltreatment on adult mental health, relatively few studies have sought to disentangle this relationship. Childhood maltreatment has been defined by Leeb, Paulozzi, Melanson, Simon and Arias (2008) as an act, which may endanger the safety or well-being of a child through acts of commission (e.g., physical, sexual and emotional abuse) or acts of omission (e.g., inadequate supervision, exposure to violent environments). Childhood maltreatment remains a pressing issue in the U.K., where findings from a nationally representative household survey conducted by the NSPCC in 2009 indicated that approximately $5.9 \%$ of children under the age of 11 experienced some form of severe maltreatment (e.g. contact sexual abuse, frequent physical abuse resulting in injuries and prolonged periods of neglect). This figure rises to $8.9 \%$ for reports of any maltreatment incident by a parent or guardian (Radford et al., 2011). Further, a review of meta-analytic studies estimated that the global prevalence of childhood maltreatment (experienced before the age of 18 ) was $12.7 \%$ for sexual abuse, $22.6 \%$ for physical abuse, $36.3 \%$ for emotional abuse, $16.3 \%$ for physical neglect and $18.4 \%$ for emotional neglect (Stoltenborgh, Bakermans-Kranenburg, Alink \& IJzendoorn, 2015).

A strong link between childhood maltreatment and adverse mental health outcomes in adulthood has been consistently demonstrated in the literature (e.g., Kessler et al, 2010; Lang, Stein, Kennedy \& Foy, 2004; Macmillan et al, 2001; Springer, Sheridan, Kuo \& Cames, 2007). Findings from the World Mental Health Survey conducted across 21 countries, indicate that childhood maltreatment is associated with increased risk for developing any DSM-IV disorder across all socio-cultural samples (Kessler et al., 2010). A large body of literature has showed that childhood maltreatment may be specifically linked with chronic posttraumatic stress disorder (PTSD) symptomology (Marshall-Berenz, Vujanovic, Bonn- 
Miller, Bernstein, \& Zvolensky, 2010), depression (Khan et al., 2015), anxiety (Nanda, Reichert, Jones, \& Flannery-Schroeder, 2015) and alcohol use disorders (Elliott et al., 2014).

It has been suggested that due to the long-term and pervasive negative impact of childhood maltreatment on adult psychopathology, there may be factors, not yet fully understood, that affect this relationship (Kessler et al., 2010). Few studies have, however, sought to disentangle the nature of the mechanisms potentially maintaining this effect (Hardy et al., 2016). Understanding the intervening variables between established relationships within the social sciences greatly benefits understanding of observed relationships and how they are realised (Baron \& Kenny, 1986). Recently, researchers have started examining the influence of indirect psychological factors in this relationship by implementing mediation analyses to examine how a variable may partially explain an observed relationship (Baron \& Kenny, 1986). For example, Shevlin, McElroy and Murphy (2014) examined the role of loneliness and found it to significantly mediate the relationship between childhood maltreatment and psychopathology.

Distress Tolerance (DT), defined as the subjective or objective ability to remain resilient to adverse internal states and external events (Leyro, Bernstein, Vujanovic, McLeish, \& Zvolensky, 2011), has also been noted as a potential mediating factor in the relationship between childhood maltreatment and adult psychopathology. The concept of DT is particularly salient in the study of traumatic stress reactions as greater understanding is sought of the mechanisms by which individuals subsequently develop mental health issues or display resilience. Marshall-Berenz et al. (2010) argued that individual perceived ability to tolerate adverse emotional states following traumatic exposure and peri-traumatic coping strategies in relation to PTSD symptomology, specifically avoidance behaviours, may influence the trajectory of symptom development and treatment outcome. Further to this, traumatic exposure in childhood has been shown to impact subsequent emotion regulation 
and psychopathological outcomes (Cook et al., 2005). It is hence argued that traumatic exposure in childhood could potentially result in disruption to the development of effective DT strategies (Briere \& Elliot, 2003) and therefore lead to distress intolerance or low DT.

More specifically, exposure to trauma in childhood may interfere with the development of self-regulation/resilience (Dunn, Nishimi, Powers, \& Bradley, 2017). It is argued that maladaptive states may become traits through altered neurobiology and developmental engraining (Perry, Pollard, Blakley, Baker, \& Vigilante, 1995). In this sense it is argued that DT serves as a proxy measure of maladaptive internal regulation processes, influenced by the presence of trauma and influencing the development of psychopathological symptoms later in life. Moreover, when faced with distress or adverse situations, individuals with low DT may be more likely to engage in maladaptive responses, such as avoidant coping, which serve as negative reinforcement strategies (e.g., avoiding negative emotions). Avoidance alleviates distress, which in turn leads to and reinforces more avoidance behaviours. Conversely, individuals with high levels of DT may be better able to cope with their negative emotions and less likely to engage in maladaptive responses (Leyro, Zvolensky, \& Bernstein, 2010). Therefore, if an individual with low DT experiences a traumatic event, they may be more likely to attempt to minimise their distress by employing maladaptive coping strategies and subsequently more likely to experience psychopathological symptoms (Leyro et al., 2010).

This theory has been supported by studies which showed that individuals with low DT are more likely to developed eating disorders (Anestis, Selby, Fink \& Joiner, 2007) and engage in drug and alcohol abuse (Buckner, Keough \& Schmidt, 2007) or self-harm behaviours (Chapman, Gratz \& Brown, 2006), all of which could be considered affect avoidant coping strategies and indicative of issues with DT. In recent years, researchers have consistently documented the role of DT in the development of specific mental health 
outcomes, such as trauma related disorders, anxiety, depression and problematic substance use. For example, in relation to PTSD, Vujanovic, Bon-Miller, Potter, Marshall and Zvolensky (2011) found that lower individual levels of DT were positively associated with several symptom clusters of PTSD, as well as overall symptom severity, in a sample of trauma exposed adults. Similarly, Marshall-Berenz et al. (2010) found that DT explained 6\% of the variance in PTSD symptom severity, while controlling for traumatic experiences and socio-demographic characteristics. Similar results have been reported in a vast majority of the existing studies examining the link between DT and PTSD (Vujanovic, Bon-Miller et al., 2011; Banducci, Connolly, Vujanovic, Alvarez, \& Bonn-Miller, 2017).

In relation to anxiety disorders, Keough, Riccardi, Timpano, Mitchell and Schmidt (2010) reported that in a sample of university students, there was a significant negative association between DT and a wide range of anxiety-related symptoms, including those that characterize social anxiety, obsessive compulsive disorder and panic disorder. Similar results were reported in a study assessing treatment-seeking university students with primary diagnoses of anxiety disorders; lower levels of DT predicted generalised anxiety (GAD), social anxiety and obsessive compulsive disorder, but not panic disorder (Laposa, Collimore, Hawley \& Rector, 2015). Indeed, Leyro et al. (2010) argued that DT is conceptually linked to anxiety as those low in DT are more likely to fail to reconcile feelings of distress and have these feelings perpetuate. In this sense it can be argued that low DT may result in psychopathological outcomes in the form of generalised anxiety disorders.

Depression has also been found to be associated with DT. Both the general population and clinical studies have found that individuals with higher levels of depression symptoms exhibit lower levels of DT (Barnhofer, Brennan, Crane, Duggan, \& Williams, 2014; Keough et al., 2010; Peterson, Davis-Becker \& Fischer, 2014). For example, Barnhofer et al. (2014) found that lower levels of DT among survivors of childhood abuse were significantly 
associated with persistent depressive symptoms. Those with higher DT were more likely to be in the remitting symptom group. Further to this, research has shown that stressful life events throughout adolescence impact those with lower DT more greatly with this group more likely to suffer subsequent depressive symptoms (Felton et al., 2018). It is believed that DT is established in childhood and this may have implication for subsequent mental health trajectories (Felton et al., 2018).

Taken together, the extant literature suggests that childhood maltreatment is associated with poor adult mental health and that low DT is a risk factor for mental ill-health. The aim of the current study was to extend this area of research by examining DT as a mediator of the relationship between childhood maltreatment and adult mental health outcomes. There is greater emerging precedent to examine the indirect relationship between childhood maltreatment and psychopathology, understanding the mechanisms of this relationship (see Shevlin et al., 2014). Research has applied mediation methods to the study of trauma and mental health outcomes with a proposed manifest variable of an underlying trait, i.e. assessing maladaptive coping as a mediator (Choi et al., 2015). Extant theoretical perspectives on DT suggest that this may qualify the development and maintenance for psychopathology (Leyro et al., 2010). This investigation therefore seeks to extend understanding of the relationship between childhood maltreatment and trauma applying mediation methodology to the manifest concept of DT to further understand the post-trauma development of psychopathology.

To the best of our knowledge, no previous study has examined the role of DT as a mediator of this relationship. Understanding the possible role of DT in the relationship between childhood maltreatment and adult mental health could have important implications for planning both prevention and intervention programmes. It was hypothesized that 1) Individuals who report experiences of childhood maltreatment will be more likely to report 
negative mental health outcomes (compared to individuals without the history of childhood maltreatment); 2) Distress intolerance will be positively associated with negative mental health outcomes; and 3) DT will mediate the relationship between childhood maltreatment and mental health outcomes.

\section{Methodology}

\section{Procedure and participants}

This study was conducted as part of a larger scheme of research examining the effects of intimate partner violence on mental health outcomes among students attending a University in Northern Ireland between October 2014 and March 2015. All procedures were approved by the institutional ethics committee. Participants were recruited via an e-mail including a web-link to complete an online survey via Qualtrics. Reminders were sent once a month over a period of six months and monthly incentives of a $£ 50$ Amazon voucher were offered. The time required to complete the survey was approximately 20-30 minutes. A total of 25,000 e-mails were distributed with a response rate of $6 \%(N=1,416)$. Participants who did not answer the relevant measures for this study and those who were missing $20 \%$ or more data on any of the relevant measures were excluded $(n=508)$. An additional 25 cases were excluded due to missing demographic information, and the remaining amount of missing data $(0.31 \%)$ was estimated using the expectation maximization algorithm in SPSS. The effective sample was composed of 642 students (153 males and 489 females) aged between 18 and 61 years $(M=24.59, S D=7.46)$. The majority were white $(97.7 \%)$, currently in some form of employment (63.2\%) and currently in a relationship (69.0\%). Full demographic information is displayed in Table 1. 
Mediating role of distress tolerance

\section{Measures}

Sociodemographic characteristics relevant to the current study included participants' sex, age and relationship status, which were included as covariates in the analyses.

Relationship status was included as a proxy of social support as this has been shown to protect against the development of psychopathology among university students (Braithwaite, Delevi \& Fincham, 2010). Relationship status was binary coded as 1) 'in a relationship' (dating, cohabiting, married) or 2) 'not in relationship' (single, widowed, separated, divorced). Students were also asked about their ethnicity, however, since $97.7 \%$ of the effective sample reported their ethnicity as White (See Table 1), this variable was excluded from the analyses.

Childhood Maltreatment was assessed using four items developed for the current study based on the measurements used by Christoffersen, Armour, Lasgaard, Andersen, and Elklit (2013). The current study collapsed the original 24 items examining the presence of abuse used by Christoffersen et al. (2013) into their respective maltreatment categories; neglect, physical assault, psychological abuse and sexual abuse before the age of 12 , which is a cut off commonly used in childhood maltreatment research (see Holt, Buckley, \& Whelan, 2017). The items used in the current study were worded as follows:

- Neglect (for example, left alone in the house for days, starved due to lack of food, made to wear dirty clothes)

- Physical assaults (for example, slapped, punched, kicked, beaten with objects, left with marks and bruising)

- Psychological (for example, humiliated in public, called names, made to feel unwanted/unloved/worthless)

- Sexual assaults (for example, experienced sexual touching, attempted, forced or completed intercourse, other sexual behaviours) 
Mediating role of distress tolerance

Response options were; "Never", "Hardly ever", "Occasionally”, “Sometimes”, "Frequently", “Almost always", and "Don't know". These responses were re-coded into binary positive or negative endorsements of maltreatment exposure. Response options "Never" or "Hardly ever" were coded as negative endorsements ('Not maltreated'), because those who experience maltreatment in a single instance or the duration of maltreatment is less than seven days, have previously been found to significantly differ in terms of mental health outcomes from those who experience sustained abuse and neglect (see Bagley \& Mallick, 2000). Response options “Occasionally" to "Almost always" were coded as positive endorsements ('Maltreated') and the response option "Don't know" was coded as missing.

Traumatic Exposure was assessed using the Stressful Life Events Screening Questionnaire (SLESQ; Goodman, Corcoran, Turner, Yuan, \& Green, 1998). The SLESQ is a 13 item screening measure of individual stressful and potentially traumatic exposure to specific stressors (e.g. abuse, assault, and the threat of harm) and other general perceived threats to individual safety (e.g. warzone exposure or any event not described by the previous items). Responses are coded as "Yes" or "No" for each stressful exposure.

PTSD was assessed using the PTSD Checklist for DSM-5 (PCL-5; Weathers, Litz, Keane, Palmieri, Marx, \& Schnurr, 2013). The PCL-5 is a 20-item inventory assessing the presence of PTSD symptomatology as outlined by the DSM-5 (APA, 2013). Questions ask respondents to report to what extent ( $0=$ "Not at all" to $4=$ "Extremely") they have been bothered by specific symptoms of PTSD in the past month in relation to their perceived worst traumatic event identified through SLESQ. Total scores range from 0 - 80. The current study used the recommended cut-off score of 33 (Weathers et al., 2013) to divide participants into symptomatic and non-symptomatic PTSD groups. The PCL-5 has demonstrated good internal consistency, reliability and validity in a variety of studies across numerous populations 
(Sveen, Bondjers \& Willebrand, 2016) and had a good internal consistency in the current sample $(\alpha=0.96)$.

Depression was assessed using the Patient Health Questionnaire-9 (PHQ-9; Kroenke, Spitzer, \& Williams, 2001). Each item within the PHQ-9 is based on one of the nine DSM-IV symptoms for major depressive disorder. Responses range from 0 ("Not at all") to 3 ("Nearly every day") and reflect the frequency of symptoms experienced in the previous two weeks. Total scores can range from 0-27 and a cut-off score of 10 was used to categorize participants into symptomatic and non-symptomatic depression groups (Kroenke et al., 2001). The internal consistency of PHQ-9 was good in the current sample $(\alpha=0.92)$.

Anxiety was assessed using the Generalized Anxiety Disorder Screener (GAD-7; Spitzer, Kroenke, Williams, \& Lowe, 2006). The GAD-7 is a seven-item questionnaire examining the frequency of various behavioural symptoms of anxiety over the past two weeks. Scores range from 0 ("Not at all") to 3 ("Nearly Every Day") yielding a possible score range of $0-21$. GAD-7 has been found to be a reliable measure of anxiety in the general population (Löwe et al., 2008) and in the current sample, it had good internal consistency ( $\alpha$ $=0.92$ ). A cut-off score of 10 was used to categorize participants into symptomatic and nonsymptomatic anxiety groups based on the recommendations of Spitzer et al. (2006).

Alcohol Use was assessed using the Alcohol Use Disorders Identification Test (AUDIT; Babor, Higgins-Biddle, Saunders, \& Monteiro, 2001), which is a 10-item measure assessing the respondents' dependence on alcohol and harmful and hazardous alcohol use. In the U.K., $72 \%$ of undergraduate students have been found to engage in frequent binge drinking behaviours (Balodis, Potenza, \& Olmstead, 2009) and we therefore utilized the cutoff score of 10 (Possible range 0-40) to categorize participants into problematic and nonproblematic alcohol use groups. The AUDIT has been shown to display sufficient reliability 
and validity as a screening tool to identify possible hazardous and harmful alcohol use (Daeppen, Yersin, Landry, Pécoud, \& Decrey, 2000). The internal reliability in the current study was good $(\alpha=0.82)$.

Distress Tolerance was assessed using the Distress Tolerance Scale (DTS; Simons \& Gaher, 2005). The DTS is a 15-item inventory measuring the subjective psychological distress experienced by the individual. Each item is rated on a scale from 1 to 5 , with one item reverse coded and hence negatively scored. Total scores may range from $0-70$. Higher total scores indicate greater perceived ability to withstand adverse psychological states, while lower scores indicate a perceived inability to withstand such states. The DTS has been shown to possess good psychometric properties, demonstrating high convergent and discriminant validity, and high internal consistency in both university student and clinical populations (Marshall-Berenz et al., 2010; Simons \& Gaher, 2005). In the current study, it had good internal consistency $(\alpha=0.94)$.

\section{Analytic plan}

Background characteristics, specifically age, gender, and relationship status, were controlled for in the analysis, as these constructs have previously been shown to influence psychopathology (see World Health Organisation, 2014). For example, gender differences have previously been noted between the mental health sequel following traumatic exposure, with females reporting more emotional difficulties and anxiety symptoms and males reporting greater suicidal ideation and alcohol and substance use disorders (Chaplin, Hong, Bergquist, \& Sinha, 2008; Afifi, 2007). Males have also been found to report higher levels of DT than females (Simons \& Gaher, 2005). Additionally, age was included as a covariate, because older individuals have been found to report more affective symptomology and fewer behavioural difficulties than younger individuals (Kiejna et al., 2015; Afifi, 2007). 
The current study implemented a similar analytic model to the work of Shevlin et al. (2014) who examined loneliness as a mediating variable of the relationship between childhood maltreatment and psychopathology. Three regression models were specified and tested using the robust maximum likelihood estimator in Mplus 7.3 (Muthén \& Muthén, 1998 - 2015). Model 1 was a multivariate logistic regression model and contained the binary coded mental health outcomes (PTSD, depression, anxiety, alcohol use) which were regressed on the childhood maltreatment variable. Childhood maltreatment was binary coded with 'Not maltreated' being the reference category. At this stage, the demographic variables were added to the model as covariates, but their paths to the mental health outcomes were fixed to zero. DT was also added as a mediator, but its paths to the dependent variables (mental health outcomes), and from the predictor variables (childhood maltreatment and covariates) were fixed to zero. This was implemented for the purposes of conducting chi-square difference tests for direct comparison of the different models. In Model 2, the paths from the covariates to the mental health outcomes were freely estimated, but the paths to and from DT remained fixed. For gender, 'female' was the reference category and for relationship status, the reference category was 'in a relationship'. Age was entered into the model as a continuous variable. This model likewise represented a multivariate logistic regression. Finally, Model 3 was the full mediation model, in which the paths to and from DT were freely estimated (See Figure 1). DT was entered into the model as a continuous variable. The effects from childhood maltreatment and the covariates to DT were linear regressions, and the paths from DT to the mental health outcomes were logistic regressions. Chi-square difference tests were used to compare Model 1 vs. Model 2 and Model 2 vs. Model 3 in order to determine the best-fitting model. All models are depicted in Figure 1.

$$
* * * \text { Figure } 1 * * *
$$


Mediating role of distress tolerance

\section{Results}

Descriptive statistics of the effective sample on childhood maltreatment, DT, and the mental health outcomes are shown in Tables 1 and 2. The majority of participants endorsed no experience of childhood maltreatment $(n=475,74.0 \%)$, with $11.7 \%$ of participants experiencing two or more forms of childhood maltreatment. Amongst those who experienced any maltreatment, the mean number of different types of childhood maltreatment experienced was $1.61(S D=.81)$. The mean DT score for participants who endorsed childhood maltreatment was $37.21(S D=14.95, M d n=37.00)$ and for participants who did not endorse childhood maltreatment, it was $41.71(S D=15.88, M d n=43.00)$. Data were found to be not normally distributed, hence the Mann Whitney U test was used, showing that this difference was significant $(U=32799.50, p<.001)$.

\section{$* * *$ Tables $1 \& 2 * * *$}

Table 3 shows the results of the regression analyses and the estimates for the indirect effects through DT. In Model 1, childhood maltreatment was found to significantly predict all mental health outcomes, suggesting that the likelihood of having a probable diagnosis of PTSD, depression, anxiety or alcohol use disorder is increased for those reporting childhood maltreatment. In Model 2, where covariates were introduced, childhood maltreatment remained a significant predictor of all mental health outcomes (see Table 3). This model provided a significantly better fit than Model 1, which did not include the covariates $\left(\Delta \chi^{2}=\right.$ $55.483, \Delta d f=12, p<.001)$. A number of covariates were found to significantly predict the mental health outcomes. Females and those who were currently not in a relationship were significantly more likely to have a probable PTSD diagnosis, females and younger individuals were more likely to meet the criteria for major depression, and males, younger 
individuals, and those currently not in a relationship were significantly more likely to have a probable alcohol use disorder (See Table 3 for odds ratios).

Model 3 (See Figure 1), which included the covariates and the mediator, provided a significantly better fit than Model $2\left(\Delta \chi^{2}=240.982, \Delta d f=8, p<.001\right)$. The odds ratios for the direct effects of childhood maltreatment on the mental health outcomes remained significant, but were reduced, ranging from $1.562(95 \% C I=1.054-2.315)$ for alcohol use disorder to 3.493 (95\% CI = 2.242-5.443) for PTSD. PTSD and depression were further significantly predicted by female gender and alcohol use was significantly predicted by younger age, male gender, and not being in a relationship (See Table 3 for odds ratios). Additionally, it was found that the indirect paths from childhood maltreatment through DT to the mental health outcomes were all statistically significant. Together with the reduced odds ratios for the direct effects of childhood maltreatment on the mental health outcomes, the results suggest that DT is a significant mediator of this relationship; as DT increases, the likelihood of having a probable diagnosis of any of the mental health outcomes decreases.

$$
* * * \text { Table } 3 * * *
$$

\section{Discussion}

The primary aim of this study was to extend the existing knowledge regarding the relationships between childhood maltreatment, DT, and mental ill-health by examining DT as a possible mediating variable. First, the rates of childhood maltreatment in the sample showed that $475(74 \%)$ respondents did not endorse any experience of childhood maltreatment. This concurs with previous literature, which has found that the majority of the population do not experience childhood maltreatment or victimisation (Burns, Lagdon, Boyda \& Armour, 2016). Of those who positively endorsed experiencing a form of childhood maltreatment, $16.7 \%$ endorsed physical abuse, $19.3 \%$ endorsed psychological abuse, $2.2 \%$ 
endorsed sexual abuse, and $3.7 \%$ endorsed neglect. The rates of these specific abuse and neglect experiences were considerably lower than the worldwide prevalence rates estimated by Stoltenborgh et al. (2015). However, the difference in prevalence rates could be due to differing populations, definitions of abuse, and the measurement of maltreatment. It should also be noted that the current sample was drawn from a university student population and those who have experienced childhood maltreatment may be less likely to attend higher education institutions, due to the negative impacts of childhood maltreatment on educational achievement and mental health (Romano, Babchishin, Marquis, \& Fréchette, 2015).

When examining the relationship between childhood maltreatment and the mental health outcomes, the results revealed that childhood maltreatment was associated with an increased likelihood for the development of PTSD, depression, anxiety, and problematic alcohol use, thus supporting our hypothesis. These findings are consistent with a large body of evidence which links childhood maltreatment to adult psychopathology (e.g., Armour et al., 2014, 2016; Kessler et al, 2010; Lauterbach \& Armour, 2016; McLafferty et al., 2015; Murphy, Shevlin, Armour \& Christoffersen, 2014; Springer et al., 2007).

The results also demonstrated that higher DT was associated with a decreased likelihood of experiencing symptoms of the four mental health disorders under investigation, again supporting our hypothesis. This suggests that higher levels of DT could be a protective factor against PTSD, depression, anxiety, and alcohol use disorder. This finding is consistent with previous research which has evidenced that low DT is associated with an increased risk for various forms of mental health disorders in adulthood (Leyro et al., 2011; Vujanovic, Bon-miller, et al., 2011). Furthermore, as previously noted, the link between low DT and psychopathology could partly be explained by the use of maladaptive coping strategies, such as alcohol misuse. It has been argued that individuals with higher DT would be expected to cope more readily with adverse situations and emotional states, thus being protected from the 
development of psychopathology (Leyro et al., 2011). On the other hand, those experiencing low DT are at elevated risk of increased negative appraisals and reduced ability to be resilient to distressing trauma related symptoms (Resick, Monson \& Chard, 2007). This in turn may increase the risk of using maladaptive coping strategies (Leyro et al., 2011), such as avoidance behaviours (Fetzner, Peluso \& Asmundson, 2014) or substance use (Buckner et al., 2007). For example, Fetzner et al. (2014) found that low DT specifically predicted avoidance and re-experiencing PTSD symptoms. The authors described the relationship as a selfperpetuating cycle, in which an individual with low DT, who had experienced a trauma, has a lowered perceived ability to effectively cope with re-experiencing symptoms. In this sense, individuals may be argued to use avoidance strategies, which perpetuate or maintain the reexperiencing symptoms (Fetzner, Peluso \& Asmundson, 2014). Consistent with this argument, Jeffries, McLeish, Kraemer, Avallone and Fleming (2016) found that low DT significantly predicted suppression, rumination, and avoidance.

Although previous studies have found that low DT is associated with poor mental health (Marshall-Berenz et al., 2010; Keough et al., 2010; Greenberg et al., 2014), to the best of our knowledge, the role of DT as a mediator in the relationship between childhood maltreatment and adult mental health, has not been previously explored. As predicted, the current study found that when DT was introduced into the model as a mediator, the strength of the relationship between childhood maltreatment and the negative mental health outcomes was reduced, supporting the hypothesis of DT as a significant mediator. This finding concurs with previous research, which showed that DT mediated the relationship between trauma exposure and the use of alcohol as a coping strategy in an adult community sample (Vujanovic, Marshal Berenz, et al., 2011). Similarly, Holliday et al., (2016) found that in a sample of trauma exposed veterans, DT mediated the relationship between trauma exposure and alcohol use. Although examining different populations and outcomes, the similarity in 
the results of these two studies and the current study suggests that higher DT results in lower rates of negative mental health outcomes and it could therefore serve as a protective factor in the relationship between childhood maltreatment and later psychopathology. Further to this, this study compliments and extends the existing literature base examining the context of childhood maltreatment as a potentially traumatic exposure influencing trait levels of distress tolerance which in turn may influence the development of psychopathology.

\section{Implications}

These findings have important implications for the development and implementation of intervention and prevention strategies that could be used specifically to assist childhood trauma survivors with lower DT to cope with their traumatic experiences. Furthermore, findings emphasise the importance of building resilience, which in the face of adversity, could protect against the development of adverse mental health outcomes. If replicated in future studies, assessment of DT could be integrated within initial clinical assessments of survivors of childhood maltreatment to possibly establish the risk of developing adverse mental health outcomes. Prevention strategies could then incorporate elements of teaching or enhancing DT. Indeed, teaching DT skills within Dialectical Behaviour Therapy for the treatment of borderline personality disorder is argued to address emotion dysregulation, which is considered central in the development of borderline personality symptoms (Lynch, Chapman, Rosenthal, Kuo, \& Linehan, 2006) that are often linked to childhood maltreatment (Hecht, Cicchetti, Rogosch, \& Crick, 2014). Similar training could be delivered to youth who have experienced childhood maltreatment to lessen their chances of developing negative mental health outcomes. 


\section{Limitations and future research}

The results of this study should be considered in light of some notable limitations. Firstly, due to the cross-sectional design of this study, the temporal order of childhood maltreatment and the onset of psychopathology could not be formally established, although it could be inferred given that childhood maltreatment was assessed in relation to the first 12 years of life and psychopathological symptomology was assessed in relation to the past few weeks/months. Additionally, the construct of DT currently lacks a unified theory and, although widely regarded as a stable trait, there is little evidence to indicate its stability across the lifespan, as much of the existing research in this area is cross-sectional (Leyro, et al., 2010). Future studies should therefore employ longitudinal designs. Thirdly, experience of trauma beyond the age of 12 was not controlled for, as it was not possible to establish from the measures used in the current study, whether the traumatic experiences reported in the SLESQ were the same or different to the ones queried with the four childhood maltreatment questions. It should however be noted that previous research has demonstrated a significant associated between childhood maltreatment and mental ill-health even when other lifetime trauma is controlled for (Spertus, Yehuda, Wong, Halligan, \& Seremetis, 2003; Khoury et al., 2010). Evidence howeyer exists to suggest that those who experience childhood maltreatment are at increased risk for subsequent victimisations (Coid et al., 2001), which could compound the effects on mental ill-health. Future studies should utilize measures that clearly differentiate between the childhood and adulthood traumatic experiences. Fourth, all constructs in the current study were assessed using self-report measures and although commonly used in psychological literature, poor memory of childhood maltreatment has been evidenced before (Williams, 1994) and could possibly lead to inaccurate results. However, it has been reported that in psychotic patients, retrospective self-reporting of childhood sexual abuse remained consistent over seven years and had good convergent validity with clinical 
case notes (Fisher et al., 2013). Fifth, the sample was predominantly white and female and generalizations to predominantly male samples or other racial backgrounds should therefore only be made with caution. The current study controlled for gender in all analyses, however, future studies may decide to employ techniques, such as moderated mediation, to further disentangle the effects of gender in this context. Sixth, the current investigation utilised a university student sample, which reduces the generalisability of the findings to other populations (Henrich, Heine, \& Norenzayan, 2010). Replications with clinical and other nonclinical samples are warranted. Finally, the survey had a low response rate of $6 \%$. The reason for this could be respondent fatigue, as the survey was advertised several weeks into the winter semester. Moreover, surveys advertised via emails and administered online are generally associated with lower response rates (Nulty, 2008). This in turn, has implications for generalizing the results to all university students.

\section{Conclusion}

Despite study limitations, the current study provides the first examination of the role of DT as a possible mediator of the relationship between childhood maltreatment and mental ill-health in adulthood. The results demonstrate that in a sample of university students from Northern Ireland, DT is a significant mediator of the relationship between childhood maltreatment and adult psychopathology. As such, the current study provides new insights into the relationship between childhood trauma and adult mental health by identifying DT as a possible risk and resilience factor in the well-established relationship. Further research in this area will be needed to provide more specific recommendations for intervention and prevention strategies. 
Mediating role of distress tolerance

\section{References}

Afifi, M. (2007). Gender differences in mental health. Singapore Medical Journal, 48(5), 385-391. Retrieved from https://sites.oxy.edu/clint/physio/article/Genderdifferencesinmentalhealth.pdf.

Anestis, M. D., Selby, E. A., Fink, E. L., \& Joiner, T. E. (2007). The multifaceted role of distress tolerance in dysregulated eating behaviors. International Journal of Eating Disorders, 40(8), 718-726. doi: 10.1002/eat.20471.

Armour, C., Shorter, G. W., Elhai, J. D., Elklit, A., \& Christoffersen, M.N. (2014). Polydrug use typologies and childhood maltreatment in a nationally representative survey of Danish young adults. Journal of Studies on Alcohol and Drugs, 75, 170-178. doi: 10.15288/jsad.2014.75.170.

Armour, C., Müllerová, J., Fletcher, S., Lagdon, S., Burns, C.R., Robinson, M., \& Robinson, J. (2016). Assessing childhood maltreatment and mental health correlates of disordered eating profiles in a nationally representative sample of English females. Social Psychiatry and Psychiatric Epidemiology, 51, 383-393. doi: 10.1007/s00127-015-1154-7.

Babor, T. F., Higgins-Biddle, J. C., Saunders, J. B., \& Monteiro, M. G. (2001). The alcohol use disorders identification test. Guidelines for use in Primary Care. Geneva, Switzerland: World Health Organization.

Bagley, C., \& Mallick, K. (2000). Prediction of sexual, emotional, and physical maltreatment and mental health outcomes in a longitudinal cohort of 290 adolescent women. Child Maltreatment, 5(3), 218-226. doi: 10.1177/1077559500005003002.

Balodis, I. M., Potenza, M. N., \& Olmstead, M. C. (2009). Binge drinking in undergraduates: Relationships with sex, drinking behaviors, impulsivity, and the perceived effects of alcohol. Behavioural Pharmacology, 20(5-6), 518-526. doi: 10.1097/FBP.0b013e328330c779.

Banducci, A. N., Connolly, K. M., Vujanovic, A. A., Alvarez, J., \& Bonn-Miller, M. O. (2017). The impact of changes in distress tolerance on PTSD symptom severity post-treatment among 
Mediating role of distress tolerance

veterans in residential trauma treatment. Journal of Anxiety Disorders, 47, 99-105. doi: 10.1016/j.janxdis.2017.01.004.

Barnhofer, T., Brennan, K., Crane, C., Duggan, D., \& Williams, J. M. G. (2014). A comparison of vulnerability factors in patients with persistent and remitting lifetime symptom course of depression. Journal of Affective Disorders, 152, 155-161. doi: 10.1016/j.jad.2013.09.001.

Baron, R. M., \& Kenny, D. A. (1986). The moderator-mediator variable distinction in social psychological research: Conceptual, strategic, and statistical considerations. Journal of Personality and Social Psychology, 51(6), 1173-1182. doi: 10.1037/0022-3514.51.6.1173.

Braithwaite, S. R., Delevi, R., \& Fincham, F. D. (2010). Romantic relationships and the physical and mental health of college students. Personal Relationships, 17(1), 1-12. doi: 10.1111/j.14756811.2010.01248.x.

Briere, J., \& Elliott, D. M. (2003). Prevalence and psychological sequelae of self-reported childhood physical and sexual abuse in a general population sample of men and women. Child Abuse \& Neglect, 27(10), 1205-1222. doi: 10.1016/j.chiabu.2003.09.008.

Buckner, J. D., Keough, M. E., \& Schmidt, N. B. (2007). Problematic alcohol and cannabis use among young adults: The roles of depression and discomfort and distress tolerance. Addictive Behaviors, 32(9), 1957-1963. doi: 10.1016/j.addbeh.2006.12.019.

Burns, C. R., Lagdon, S., Boyda, D., \& Armour, C. (2016). Interpersonal polyvictimization and mental health in males. Journal of Anxiety Disorders, 40, 75-82. doi: 10.1016/j.janxdis.2016.04.002.

Chaplin, T. M., Hong, K., Bergquist, K., \& Sinha, R. (2008). Gender differences in response to emotional stress: an assessment across subjective, behavioral, and physiological domains and relations to alcohol craving. Alcoholism: Clinical and Experimental Research, 32(7), 12421250. doi: 10.1111/j.1530-0277.2008.00679.x. 
Mediating role of distress tolerance

Chapman, A. L., Gratz, K. L., \& Brown, M. Z. (2006). Solving the puzzle of deliberate self-harm: The experiential avoidance model. Behaviour Research and Therapy, 44(3), 371-394. doi: 10.1016/j.brat.2005.03.005

Choi, K. W., Sikkema, K. J., Velloza, J., Marais, A., Jose, C., Stein, D. J., ... Joska, J. A. (2015). Maladaptive coping mediates the influence of childhood trauma on depression and PTSD among pregnant women in South Africa. Archives of Women's Mental Health, 18(5), 731738. doi: $10.1007 / \mathrm{s} 00737-015-0501-8$

Christoffersen, M. N., Armour, C., Lasgaard, M., Andersen, T. E., \& Elklit, A. (2013). The prevalence of four types of childhood maltreatment in Denmark. Clinical Practice and Epidemiology in Mental Health: CP \& EMH, 9, 149-156. doi: $10.2174 / 1745017901309010149$.

Coid, J., Petruckevitch, A., Feder, G., Chung, W., Richardson, J., \& Moorey, S. (2001). Relation between childhood sexual and physical abuse and risk of revictimisation in women: A crosssectional survey. The Lancet, 358(9280), 450-454. doi: 10.1016/S0140-6736(01)05622-7.

Cook, A., Spinazzola, J., Ford, J., Lanktree, C., Blaustein, M., Cloitre, M., . . van der Kolk , B. (2005). Complex trauma in children and adolescents. Psychiatric Annals, 35(5), 390-398. doi: 10.3928/00485713-20050501-05.

Daeppen, J., Yersin, B., Landry, U., Pécoud, A., \& Decrey, H. (2000). Reliability and validity of the alcohol use disorders identification test (AUDIT) imbedded within a general health risk screening questionnaire: Results of a survey in 332 primary care patients. Alcoholism: Clinical and Experimental Research, 24(5), 659-665. doi: 10.1111/j.15300277.2000.tb02037.x.

Dunn, E. C., Nishimi, K., Powers, A., \& Bradley, B. (2017). Is developmental timing of trauma exposure associated with depressive and post-traumatic stress disorder symptoms in 
Mediating role of distress tolerance

adulthood? Journal of Psychiatric Research, 84, 119-127. doi:

10.1016/j.jpsychires.2016.09.004

Elliott, J. C., Stohl, M., Wall, M. M., Keyes, K. M., Goodwin, R. D., Skodol, A. E., ... \& Hasin, D. S. (2014). The risk for persistent adult alcohol and nicotine dependence: the role of childhood maltreatment. Addiction, 109(5), 842-850. doi: 10.1111/add.12477.

Felton, J. W., Collado, A., Havewala, M., Shadur, J. M., MacPherson, L., \& Lejuez, C. W. (2018). Distress Tolerance Interacts With Negative Life Events to Predict Depressive Symptoms Across Adolescence. Journal of Clinical Child \& Adolescent Psychology, Advance online publication. doi: 10.1080/15374416.2017.1405354.

Fetzner, M. G., Peluso, D. L., \& Asmundson, G. J. (2014). Tolerating distress after trauma: differential associations between distress tolerance and posttraumatic stress symptoms. Journal of Psychopathology and Behavioral Assessment, 36(3), 475-484. doi: 10.1007/s10862-014-9413-6.

Fisher, H. L., Schreier, A., Zammit, S., Maughan, B., Munafò, M. R., Lewis, G., \& Wolke, D. (2013). Pathways between childhood victimization and psychosis-like symptoms in the ALSPAC birth cohort. Schizophrenia Bulletin, 39(5), 1045-1055. doi: $10.1093 / \mathrm{schbul} / \mathrm{sbs} 088$.

Goodman, L., Corcoran, C., Turner, K., Yuan, N., \& Green, B. (1998). Assessing traumatic event exposure: General issues and preliminary findings for the Stressful Life Events Screening Questionnaire. Journal of Traumatic Stress, 11(3), 521-542. doi: 10.1023/A:1024456713321.

Greenberg, L. P., Martindale, S. L., Collum, S. P., \& Dolan, S. L. (2014). Distress tolerance as a predictor of depressive and posttraumatic stress symptoms in a substance use disorder inpatient treatment sample. Traumatic Stress Disorders \& Treatment, 3(2), 1-11. doi: 10.4172/2324-8947.1000123. 
Mediating role of distress tolerance

Hardy, A., Emsley, R., Freeman, D., Bebbington, P., Garety, P. A., Kuipers, E. E., ... \& Fowler, D. (2016). Psychological mechanisms mediating effects between trauma and psychotic symptoms: the role of affect regulation, intrusive trauma memory, beliefs, and depression. Schizophrenia Bulletin, 42(1), S34-S43. doi: 10.1093/schbul/sbv175.

Hecht, K. F., Cicchetti, D., Rogosch, F. A., \& Crick, N. R. (2014). Borderline personality features in childhood: The role of subtype, developmental timing, and chronicity of child maltreatment. Development and Psychopathology, 26(03), 805-815. doi: 10.1017/S0954579414000406.

Henrich, J., Heine, S. J., \& Norenzayan, A. (2010). Beyond WEIRD: Towards a broad-based behavioral science. Behavioral and Brain Sciences, 33(2-3), 111-135. doi: 10.1017/S0140525X0999152X.

Holliday, S. B., Pedersen, E. R., \& Leventhal, A. M. (2016). Depression, posttraumatic stress, and alcohol misuse in young adult veterans: The transdiagnostic role of distress tolerance. Drug and Alcohol Dependence, 161, 348-355. doi: 10.1016/j.drugalcdep.2016.02.030.

Holt, S., Buckley, H., \& Whelan, S. (2008). The impact of exposure to domestic violence on children and young people: A review of the literature. Child Abuse \& Neglect, 32(8), 797-810. doi: 10.1016/j.chiabu.2008.02.004.

Jeffries, E. R., McLeish, A. C., Kraemer, K. M., Avallone, K. M., \& Fleming, J. B. (2016). The Role of Distress Tolerance in the Use of Specific Emotion Regulation Strategies. Behavior Modification, 40(3), 439-451. doi: 10.1177/0145445515619596.

Keough, M. E., Riccardi, C. J., Timpano, K. R., Mitchell, M. A., \& Schmidt, N. B. (2010). Anxiety symptomatology: The association with distress tolerance and anxiety sensitivity. Behavior Therapy, 41(4), 567-574. doi: 10.1016/j.beth.2010.04.002.

Kessler, R. C., McLaughlin, K. A., Green, J. G., Gruber, M. J., Sampson, N. A., Zaslavsky, A. M., . . .Williams, D. R. (2010). Childhood adversities and adult psychopathology in the WHO 
Mediating role of distress tolerance

world mental health surveys. The British Journal of Psychiatry: The Journal of Mental Science, 197(5), 378-385. doi: 10.1192/bjp.bp.110.080499.

Khan, A., McCormack, H. C., Bolger, E. A., McGreenery, C. E., Vitaliano, G., Polcari, A., \& Teicher, M. H. (2015). Childhood maltreatment, depression, and suicidal ideation: critical importance of parental and peer emotional abuse during developmental sensitive periods in males and females. Frontiers in Psychiatry, 6(42), 1-30. doi: 10.3389/fpsyt.2015.00042.

Khoury, L., Tang, Y. L., Bradley, B., Cubells, J. F., \& Ressler, K. J. (2010). Substance use, childhood traumatic experience, and posttraumatic stress disorder in an urban civilian population. Depression and Anxiety, 27(12), 1077-1086. doi: 10.1002/da.20751.

Kiejna, A., Piotrowski, P., Adamowski, T., Moskalewicz, J., Wciórka, J., Stokwiszewski, J., Rabczenko, D., \& Kessler, R. C. (2015). The prevalence of common mental disorders in the population of adult Poles by sex and age structure-an EZOP Poland study. Psychiatr. Pol, 49(1), 15-27. doi: 10.12740/PP/30811.

Kroenke, K., Spitzer, R. L., \& Williams, J. B. (2001). The Phq-9. Journal of General Internal Medicine, 16(9), 606-613. doi: 10.1046/j.1525-1497.2001.016009606.x.

Laposa, J. M., Collimore, K. C., Hawley, L. L., \& Rector, N. A. (2015). Distress tolerance in OCD and anxiety disorders, and its relationship with anxiety sensitivity and intolerance of uncertainty. Journal of Anxiety Disorders, 33, 8-14. doi: 10.1016/j.janxdis.2015.04.003.

Lang, A. J., Stein, M. B., Kennedy, C. M., \& Foy, D. W. (2004). Adult psychopathology and intimate partner violence among survivors of childhood maltreatment. Journal of Interpersonal Violence, 19(10), 1102-1118. doi: 10.1177/0886260504269090.

Lauterbach, D., \& Armour, C. (2016). Symptom trajectories among child survivors of maltreatment: Findings from the Longitudinal Studies of Child Abuse and Neglect (LONGSCAN). Journal of Abnormal Child Psychology, 44(2), 369-379. doi: 10.1007/s10802-015-9998-6. 
Mediating role of distress tolerance

Leeb, R. T., Paulozzi, L., Melanson, C., Simon, T., \& Arias, I. (2008). Child maltreatment surveillance: Uniform definitions for public health and recommended data elements. (No. 1.0). Atlanta, GA: Center for Disease Control and Prevention, National Center for Injury Prevention and Control. Retrieved from https://www.cdc.gov/violenceprevention/pdf/cm_surveillance-a.pdf.

Leyro, T. M., Bernstein, A., Vujanovic, A. A., McLeish, A. C., \& Zvolensky, M. J. (2011). Distress tolerance scale: A confirmatory factor analysis among daily cigarette smokers. Journal of Psychopathology and Behavioral Assessment, 33(1), 47-57. doi: 10.1007/s10862-010-9197-2.

Leyro, T. M., Zvolensky, M. J., \& Bernstein, A. (2010). Distress tolerance and psychopathological symptoms and disorders: A review of the empirical literature among adults. Psychological Bulletin, 136(4), 576. doi: 10.1037/a0019712.

Lynch, T. R., Chapman, A. L., Rosenthal, M. Z., Kuo, J. R., \& Linehan, M. M. (2006). Mechanisms of change in dialectical behavior therapy: Theoretical and empirical observations. Journal of Clinical Psychology, 62(4), 459-480. doi: 10.1002/jclp.20243.

MacMillan, H. L., Fleming, J. E., Streiner, D. L., Lin, E., Boyle, M. H., Jamieson, E., . . Beardslee, W. R. (2001). Childhood abuse and lifetime psychopathology in a community sample. American Journal of Psychiatry, 158(11), 1878-1883. doi: 10.1176/appi.ajp.158.11.1878.

Marshall-Berenz, E. C., Vujanovic, A. A., Bonn-Miller, M. O., Bernstein, A., \& Zvolensky, M. J. (2010). Multimethod study of distress tolerance and PTSD symptom severity in a traumaexposed community sample. Journal of Traumatic Stress, 23(5), 623-630. doi: 10.1002/jts.20568.

McLafferty, M., Armour, C., McKenna, A., O’Neill, S., Murphy, S., \& Bunting, B. (2015). Childhood adversity profiles and adult psychopathology in a representative Northern Ireland study. Journal of Anxiety Disorders, 35, 42-48. doi: 10.1016/j.janxdis.2015.07.004. 
Mediating role of distress tolerance

Murphy, S., Shevlin, M., Armour, C., Elklit, A., \& Christoffersen, M. (2014). Childhood adversity and PTSD experiences: testing a multiple mediation model. Traumatology, 20, 225-231. doi: 10.1037/h0099838.

Muthén, L. K., \& Muthén, B. O. (1998 - 2015). Mplus 7.3 (Seventh ed.). Los Angeles, CA: Muthén \& Muthén.

Nanda, M. M., Reichert, E., Jones, U. J., \& Flannery-Schroeder, E. (2015). Childhood Maltreatment and Symptoms of Social Anxiety: Exploring the Role of Emotional Abuse, Neglect, and Cumulative Trauma. Journal of Child \& Adolescent Trauma, 1-7. doi: 10.1002/da.20909.

Perry, B. D., Pollard, R. A., Blakley, T. L., Baker, W. L., \& Vigilante, D. (1995). Childhood trauma, the neurobiology of adaptation, and "use-dependent" development of the brain: How "states" become "traits." Infant Mental Health Journal, 16(4), 271-291. https://doi.org/10.1002/10970355(199524)16:4<271::AID-IMHJ2280160404>3.0.CO;2-B

Peterson, C. M., Davis-Becker, K., \& Fischer, S. (2014). Interactive role of depression, distress tolerance and negative urgency on non-suicidal self-injury. Personality and Mental Health, 8(2), 151-160. doi: 10.1002/pmh.1256.

Radford, L., Corral, S., Bradley, C., Fisher, H., Bassett, C., Howat, N., \& Collishaw, S. (2011). Child abuse and neglect in the UK today. (No. 1.0). London: NSPCC. Retrieved from https://www.nspcc.org.uk/globalassets/documents/research-reports/child-abuse-neglect-uktoday-research-report.pdf.

Resick, P. A., Monson, C. M., \& Chard, K. M. (2007). Cognitive processing therapy: Veteran/military version. Washington, DC: Department of Veterans Affairs.

Romano, E., Babchishin, L., Marquis, R., \& Fréchette, S. (2015). Childhood maltreatment and educational outcomes. Trauma, Violence, \& Abuse, 16(4), 418-437. doi: $10.1177 / 1524838014537908$. 
Mediating role of distress tolerance

Shevlin, M., McElroy, E., \& Murphy, J. (2015). Loneliness mediates the relationship between childhood trauma and adult psychopathology: Evidence from the adult psychiatric morbidity survey. Social Psychiatry and Psychiatric Epidemiology, 50(4), 591-601. doi: 10.1007/s00127-014-0951-8.

Simons, J. S., \& Gaher, R. M. (2005). The distress tolerance scale: Development and validation of a self-report measure. Motivation and Emotion, 29(2), 83-102. doi: 10.1007/s11031-005-79553.

Spertus, I. L., Yehuda, R., Wong, C. M., Halligan, S., \& Seremetis, S. V. (2003). Childhood emotional abuse and neglect as predictors of psychological and physical symptoms in women presenting to a primary care practice. Child Abuse \& Neglect, 27(11), 1247-1258. doi: 10.1016/j.chiabu.2003.05.001.

Spitzer, R. L., Kroenke, K., Williams, J. B., \& Löwe, B. (2006). A brief measure for assessing generalized anxiety disorder: The GAD-7. Archives of Internal Medicine, 166(10), 10921097. doi: 10.1001/archinte.166.10.1092.

Springer, K. W., Sheridan, J., Kuo, D., \& Carnes, M. (2007). Long-term physical and mental health consequences of childhood physical abuse: Results from a large population-based sample of men and women. Child Abuse \& Neglect, 31(5), 517-530. doi: 10.1016/j.chiabu.2007.01.003.

Stoltenborgh, M., Bakermans-Kranenburg, M. J., Alink, L. R., \& IJzendoorn, M. H. (2015). The Prevalence of Child Maltreatment across the Globe: Review of a Series of Meta-Analyses. Child Abuse Review, 24(1), 37-50. doi: 10.1002/car.2353.

Sveen, J., Bondjers, K., \& Willebrand, M. (2016). Psychometric properties of the PTSD Checklist for DSM-5: a pilot study. European Journal of Psychotraumatology, 7. doi: 10.3402/ejpt.v7.30165.

Vujanovic, A. A., Bonn-Miller, M. O., Potter, C. M., Marshall-Berenz, E. C., \& Zvolensky, M. J. (2011). An evaluation of the relation between distress tolerance and posttraumatic stress 
Mediating role of distress tolerance

within a trauma-exposed sample. Journal of Psychopathology and Behavioral Assessment, 33(1), 129-135. doi: 10.1007/s10862-010-9209-2.

Vujanovic, A. A., Litz, B. T., \& Farris, S. G. (2015). Distress tolerance as risk and maintenance factor for PTSD: Empirical and clinical implications. In C. R. Martin, V. R. Preedy, \& V. B. Patel (Eds.), Comprehensive guide to posttraumatic stress disorder. London: Springer International Publishing. doi: 10.1007/978-3-319-08613-2_66-1.

Vujanovic, A. A., Marshall-Berenz, E. C., \& Zvolensky, M. J. (2011). Posttraumatic stress and alcohol use motives: A test of the incremental and mediating role of distress tolerance. Journal of Cognitive Psychotherapy, 25(2), 130-141. doi: 10.1891/0889-8391.25.2.130.

Weathers, F., Litz, B., Keane, T., Palmieri, P., Marx, B., \& Schnurr, P. (2013). The PTSD checklist for DSM-5 (PCL-5). Scale Available from the National Center for PTSD at www.ptsd.va.gov.

Williams, L. M. (1994) Recall of childhood trauma: a prospective study of women's memories of child sexual abuse. Journal of Consulting and Clinical Psychology, 62(6): 1167-1176. doi: 10.1037/0022-006X.62.6.1167.

World Health Organization. (2014). Social determinants of mental health. World Health Organization. WHO document Production Services, Geneva, Switzerland. 
Mediating role of distress tolerance

Table 1: Demographic information and childhood maltreatment endorsements $(N=642)$

$\begin{array}{ll}\text { Variable } & \text { N }(\%)\end{array}$

\section{Demographics}

Gender

Male

$153(23.8)$

Female

$489(76.2)$

Age

$18-20$

$210(32.7)$

21-30

$332(51.7)$

$31-40$

$63(9.8)$

41-50

$29(4.5)$

$51-60$

$7(1.1)$

61-70

$1(0.2)$

Employment

Employed

406 (63.2)

Unemployed

$236(36.8)$

Ethnicity

White

$627(97.7)$

Other

$15(2.3)$

Relationship status

In relationship

$443(69.0)$

Not in relationship

$199(31.0)$

\section{Maltreatment}

Any childhood maltreatment

Maltreated

$167(26.0)$

Not maltreated

$475(74.0)$

Type of childhood maltreatment

Psychological

$124(19.3)$

Physical

$107(16.7)$

Neglect

$24(3.7)$ 
Mediating role of distress tolerance

Sexual

$14(2.2)$

Number of childhood maltreatment types endorsed

0

$475(74.0)$

1

$92(14.3)$

2

$55(8.6)$

3

$13(2.0)$

4

$7(1.1)$ 
Mediating role of distress tolerance

Table 2: Descriptive statistics and bivariate correlations between distress tolerance and the mental health outcomes

\begin{tabular}{|c|c|c|c|c|c|}
\hline & $\begin{array}{l}\text { Distress } \\
\text { tolerance }\end{array}$ & PTSD & Depression & Anxiety & $\begin{array}{l}\text { Alcohol } \\
\text { use }\end{array}$ \\
\hline \multicolumn{6}{|l|}{$\begin{array}{l}\text { Descriptive } \\
\text { statistics }\end{array}$} \\
\hline $\mathrm{M} \pm \mathrm{SD}$ & $40.54 \pm 15.76$ & $17.52 \pm 18.97$ & $7.45 \pm 6.59$ & $6.12 \pm 5.55$ & $8.57 \pm 5.95$ \\
\hline $\begin{array}{l}\text { Symptomatic group } \\
n(\%)\end{array}$ & - & 134 (20.9) & $174(27.1)$ & $\begin{array}{l}127 \\
(19.8)\end{array}$ & $\begin{array}{l}198 \\
(30.8)\end{array}$ \\
\hline \multicolumn{6}{|l|}{ Correlations } \\
\hline PTSD & $-.345^{* *}$ & - & - & & \\
\hline Depression & $-.388^{*}$ & $.675^{* *}$ & - & & \\
\hline Anxiety & $-.405^{* *}$ & $.630 * *$ & $.802 * *$ & - & \\
\hline Alcohol use & $-.079 *$ & $.089 *$ & $107 * *$ & .066 & - \\
\hline
\end{tabular}

Note. Spearman's rho correlations. $* *<.01$ (2-tailed); $*<.05$ (2-tailed). 
Mediating role of distress tolerance

Table 3: Odds ratios and confidence intervals for the direct and indirect effects

\begin{tabular}{lllll}
\hline Variable & $\begin{array}{l}\text { Model 1 - OR } \\
(95 \% C I)\end{array}$ & $\begin{array}{l}\text { Model 2 - OR } \\
(95 \% C I)\end{array}$ & $\begin{array}{l}\text { Model 3 - OR } \\
(95 \% C I)\end{array}$ & $\begin{array}{l}\text { Indirect effect } \\
\text { (reference category) }\end{array}$
\end{tabular}

PTSD

\begin{tabular}{|c|c|c|c|c|}
\hline $\begin{array}{l}\text { Childhood } \\
\text { maltreatment }\end{array}$ & $\begin{array}{l}3.911(2.615- \\
5.851)^{* * *}\end{array}$ & $\begin{array}{l}3.839(2.549- \\
5.783)^{* * *}\end{array}$ & $\begin{array}{l}3.493(2.242- \\
5.443)^{* * *}\end{array}$ & $\begin{array}{l}0.317 \\
(0.092)^{* *}\end{array}$ \\
\hline Age & - & $\begin{array}{l}0.998(0.973- \\
1.025)\end{array}$ & $\begin{array}{l}1.015(0.988- \\
1.042)\end{array}$ & $\begin{array}{l}-0.016 \\
(0.005) * *\end{array}$ \\
\hline $\begin{array}{l}\text { Male gender } \\
\text { (female })\end{array}$ & - & $\begin{array}{l}0.566(0.341- \\
0.939)^{*}\end{array}$ & $\begin{array}{l}0.575(0.338- \\
0.976)^{*}\end{array}$ & $-0.099(0.096)$ \\
\hline $\begin{array}{l}\text { Not in relationship } \\
\text { (in a relationship) }\end{array}$ & - & $\begin{array}{l}1.559(1.023- \\
2.375)^{*}\end{array}$ & $\begin{array}{l}1.478(0.927- \\
2.356)\end{array}$ & $0.070(0.085)$ \\
\hline Distress tolerance & - & - & $\begin{array}{l}0.940(0.926- \\
0.954)^{* * *}\end{array}$ & \\
\hline
\end{tabular}

\section{Depression}

Childhood

$2.671(1.833-$

$2.861(1.946-$

$2.514(1.687-$

0.250

maltreatment

$3.892)^{* * *}$

$4.208)^{* * *}$

$3.746) * * *$

$(0.074) * *$

Age

0.972 (0.946-

0.981 (0.955-

$-0.013$

0.998)*

1.009)

$(0.004) * *$

Male gender

$0.571(0.359$ -

$0.578(0.353-$

$-0.078(0.075)$

(female)

$0.908)^{*}$

$0.945)^{*}$

Not in relationship

$1.130(0.766-$

1.059 (0.704-

$0.055(0.067)$

(in a relationship)

$1.668)$

$1.595)$

Distress tolerance

0.953 (0.941-

$0.965)^{* * *}$

\section{Anxiety}

Childhood

2.871 (1.908-

3.095 (2.044-

2.733 (1.775-

0.289

maltreatment

$4.319)^{* * *}$

$4.685)^{* * *}$

$4.209)^{* * *}$

$(0.086)^{* *}$

Age

0.972 (0.944-

$0.983(0.953$

$-0.015$

1.002)

1.015)

$(0.005)^{* *}$

Male gender

0.625 (0.369-

0.647 (0.367-

$-0.090(0.087)$

(female)

1.059)

1.142) 
Mediating role of distress tolerance

\begin{tabular}{|c|c|c|}
\hline $\begin{array}{l}\text { Not in relationship } \\
\text { (in a relationship) }\end{array}$ & $\begin{array}{l}0.932(0.600- \\
1.447)\end{array}$ & $\begin{array}{l}0.823(0.513- \\
1.321)\end{array}$ \\
\hline Distress tolerance & - & $\begin{array}{l}0.945(0.931- \\
0.959) * * *\end{array}$ \\
\hline
\end{tabular}

$\begin{array}{lllll}\text { Alcohol use } & & & \\ \text { Childhood } & 1.472(1.015- & 1.663(1.128- & 1.562(1.054- & 0.068(0.034)^{*} \\ \text { maltreatment } & 2.134)^{*} & 2.453)^{*} & 2.315)^{*} & \\ \text { Age } & - & 0.955(0.928- & 0.958(0.931- & -0.003(0.002)^{*} \\ & & 0.983)^{* *} & 0.987)^{* *} & \\ \text { Male gender } & - & 1.648(1.115- & 1.690(1.141- & -0.021(0.023) \\ \text { female }) & 2.434)^{*} & 2.505)^{* *} & \\ \text { Not in relationship } & - & 1.629(1.130- & 1.610(1.115- & 0.015(0.020) \\ \text { (in a relationship) } & & 2.349)^{* *} & 2.326)^{*} & \\ \text { Distress tolerance } & - & & & 0.987(0.976- \\ \end{array}$

Note. ${ }^{* * *} p<.001 ; * * p<.01 ; * p<.05$ 
Mediating role of distress tolerance

Fig. 1: Conceptual Model Diagram

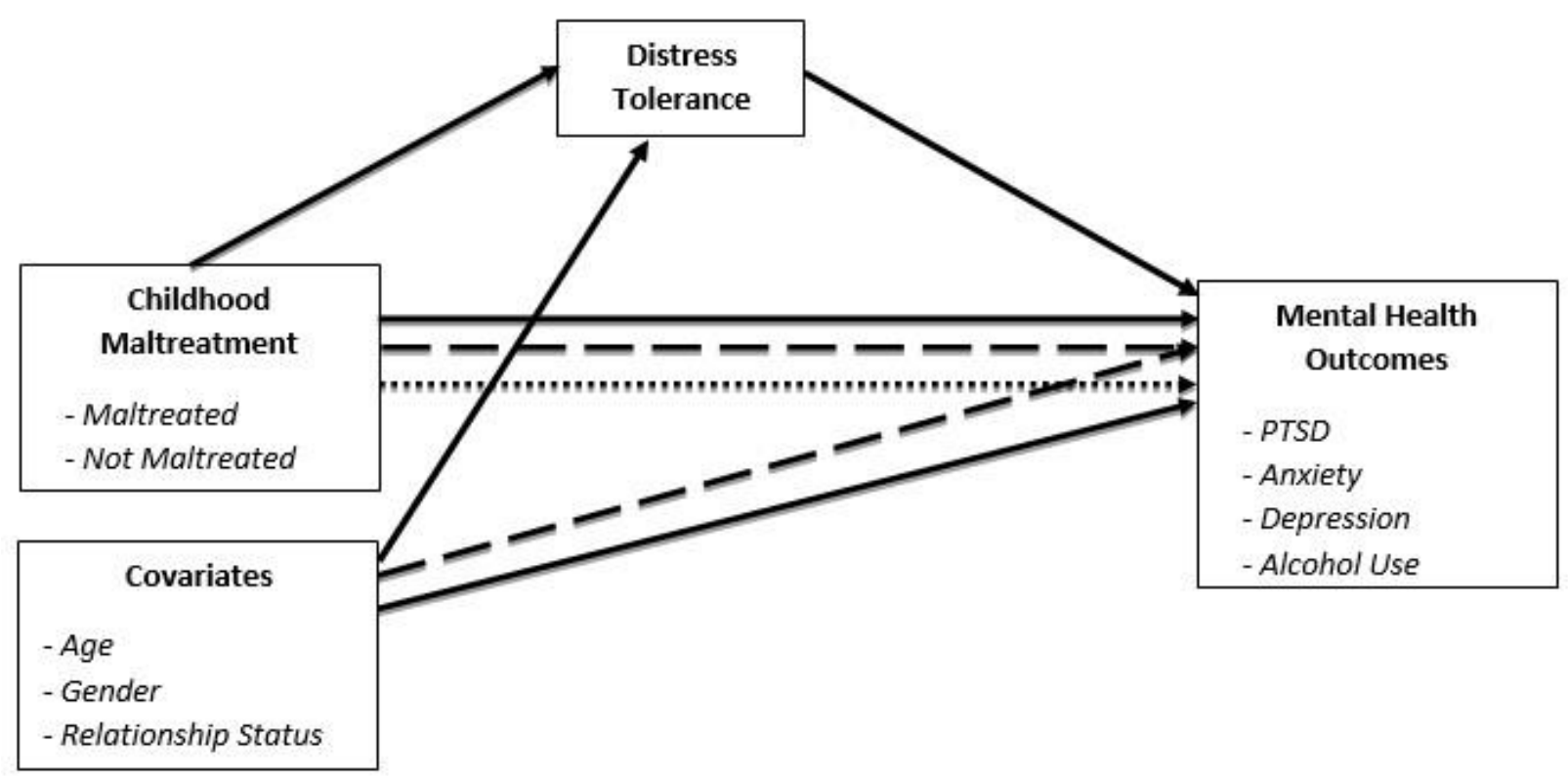

$$
\begin{aligned}
& \text { Legend } \\
& \text {........ Model } 1 \\
& \longrightarrow \rightarrow \text { Model } 2 \\
& \text { Model } 3
\end{aligned}
$$

